\title{
Camera-Based Road Damage Detection System with Edge Detection Algorithm
}

\author{
Rosida Vivin Nahari ${ }^{1}$, Riza Alfita ${ }^{2}$, Hairul Anam ${ }^{3}$, Kunto Aji Wibisono ${ }^{4}$, Mirza Pramudia ${ }^{5}$ \\ \{rosida_vn@yahoo.com ${ }^{1}$, yogya_001@yahoo.co.id ${ }^{2}$, hairulanams23@gmail.com ${ }^{3}$ \} \\ Faculty of Engineering, University of Trunojoyo Madura, Bangkalan, Indonesia ${ }^{12345}$
}

\begin{abstract}
Road is one of the transportation infrastructure which is very important for vehicle in riding activity. The vehicle is growing every year, road infastructure should be getting attention for comfortable and safety in riding. However, there are still many apprehensive road condition in the form of damaged roads, especially potholes. One of the problem in repairing road is road damage detection process which is done manually by the human, by this way the process needs a longer time. This research develops road damage detection system by using image processing and road damage mapping which are saved in database. This system uses webcam for capturing the road in real time, webcam is located in font of vehicle and GPS module is used for marking road damage location which is controlled by arduino uno microcontroller.
\end{abstract}

Keywords: road damage, detection, webcams, image processing, GPS module.

\section{Introduction}

Road damage that occurs on public roads is very common in many regions. These conditions would also disrupt the convenience and endanger the road users. Accidents often occur because riders are not able to control and anticipate the damaged road. Moreover, there are also many of such accidents that take the lives of the riders. The cause of road damage can be caused by frequent overloaded trucks passing through roads, frequent waterlogging and lack of road maintenance. According to the Maintenance Manual of Highways No. 03/MN/B/1983, road damage is classified into: cracking, distortion, disintegration, polish aggregate, bleeding or flushing, decreasing excavation or utility planting [1].

One of the consequences of road damage is the occurrence of accidents. The road personnel in improving the road infrastructure is still done fully by using human power, so the road repair process takes a relatively long time. Therefore, the title of this research is a camera-based road damage detection system with edge detection algorithm.

Based on previous research by Barsyah Dwi Idestio and Tjokorda Agung BW, (2013) in the journal entitled: "Alternative Measurement Based on Video Data of Pothole Area By Applying Threshold-Based Marking and GLCM". This study developed a system of detection and measurement of road damage, especially potholes, based on video data, by applying threshold-based marking and GLCM. The system consisted of two stages, beginning with detecting the possibility of the pothole area by using threshold-based marking which was followed by classification based on the characteristic vector obtained through GLCM. The test results showed that the system accuracy level was $91.67 \%$ with a processing time of 0.08 seconds for each frame [2].

ICCSET 2018, October 25-26, Kudus, Indonesia

Copyright () 2018 EAI

DOI 10.4108/eai.24-10-2018.2280530 
In previous research conducted by Rizki Anzhar Ramadlan Putra, et al (2013) in the journal entitled: "Implementation of Image Registration For Recording Condition of Highway by Using Global Positioning System (GPS)". This study used a camera which was placed in front of a vehicle that aimed to facilitate the scanning of the highway for image processing. This study also used GPS that would show the position of the vehicle in every location of the highway which was passed through by the vehicle, where the results of this image processing would be processed into image registration with the aim to obtain a new image form so that users could know in detail the condition of the highway at each point. The methods used were canny edge detection and hough line transformation. The highest error result obtained was in the road conditions that were slightly cracked and wet and the system could work optimally at $10-20 \mathrm{~km} / \mathrm{h}$ speed with an average error rate of $33-38 \%$ [3].

Further research was conducted by Andy Suryowinoto and Abdul Hamid (2017), in a journal entitled: "The Use of Digital Image Processing With Edge Detection Algorithm In Identifying Road Contour Damage". The system created in this journal used the process of digital image processing with a method used to identify the potholes by using canny edge detection algorithm. The image capture process was done by using a digital camera with a resolution of $640 \times 480$ pixels. This system could identify road contour damage, especially potholes, with accuracy above $80 \%$ in still image capture [4].

The methode that we purpose use arduino uno as module GPS for marking road damage location. Our research segmented road damage using canny detector and capture video of kamal street in Bangkalan district..

\section{Research Methods}

The system designed in this study is used to detect road damage by receiving input in the form of asphalt surface video data from webcam and it will be processed by computer. Image data from the video consists of multiple frame images which is displayed simultaneously, and continuously processed by using image-processing techniques to detect road damage objects. This system is divided into two processes, namely: the process of detecting road damage; and the process of storing the data into the database. In general, the way the system works is illustrated in figure 1.

\subsection{Designing Global Positioning System Module}

GPS (Global Positioning System) is a system capable of providing a precise location on earth, at anytime, under any circumstances and anywhere. The built-in GPS is guided by about 24 satellites housed in a particular orbit. Satellites are monitored continuously through ground stations that exist throughout the earth [5]. The satellite transmits signals that can be captured by anyone equipped with a GPS Receiver [6]. With this receiver, we can know exactly where our location on earth today. The type of GPS Receiver used in this research is UO NEO 6M GPS Module.

The working principle of GPS is the measurement of range between GPS Receiver with satellite. Satellites also provide information on the location of the orbit where the satellite is currently on the surface of the earth [7]. 


\subsection{Arduino Uno}

Arduino Uno is a microcontroller board based on ATmega328. The Arduino Uno has 14 digital input/output pins (of which 6 of 14 can be used as PWM outputs), 6 analog inputs, a $16 \mathrm{MHz}$ ceramic resonator, a USB connection, a power jack, an ICSP header, and a reset button [7]. Arduino Uno is used to process the data of GPS module which will be sent to the computer.

In figure 3 below, it can be explained that U-Block NEO 6M GPS Module has 4 pins, namely: VCC, GND, RX and TX. This GPS requires a supply voltage of 5 Volts and GND, both of which are available by Arduino Uno. RX and TX pins are connected to pin 10 and 11 of Arduino Uno.

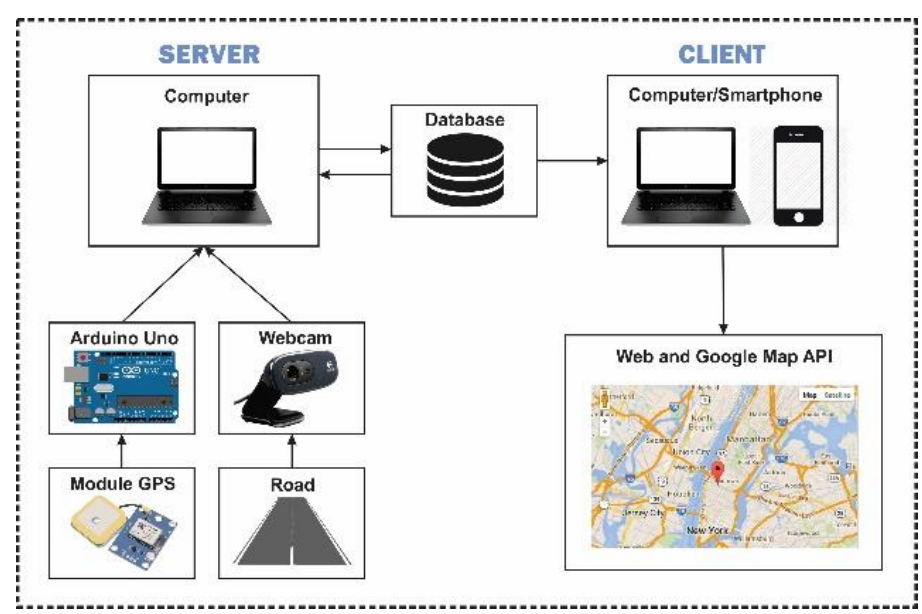

Fig. 1. How the System Works Generally.

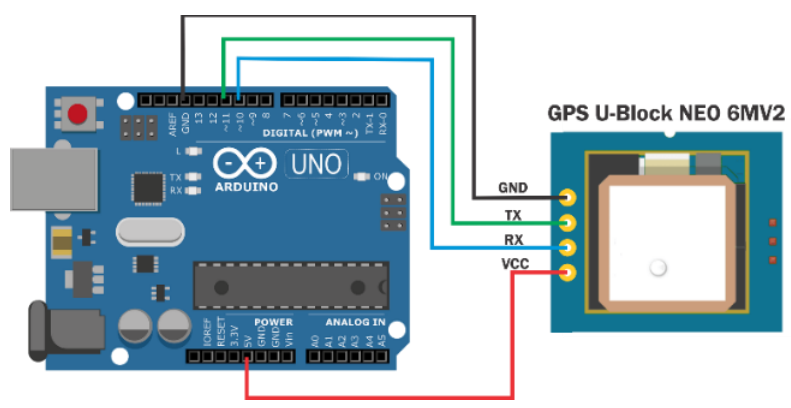

Fig. 2. Schematic of GPS Module with Arduino Uno.

The explanation of each block in figure 3 is as follows: 
a) Data acquisition is the process of taking video data from a webcam that will be processed on the computer.

b) Preprocessing is an image enhancement process to maximize the road damage detection process. Prepocessing is done by cutting the top of the image or ROI (Region of Interest) and RGB image conversion to grayscale image.

c) Road damage detection, this process uses canny type edge detection and calculates the average color value of the image.

Data saving, some data stored in the database, that is the value of latitude and longitude of GPS, as well as road damage image (capture results) of the system stored on the computer.

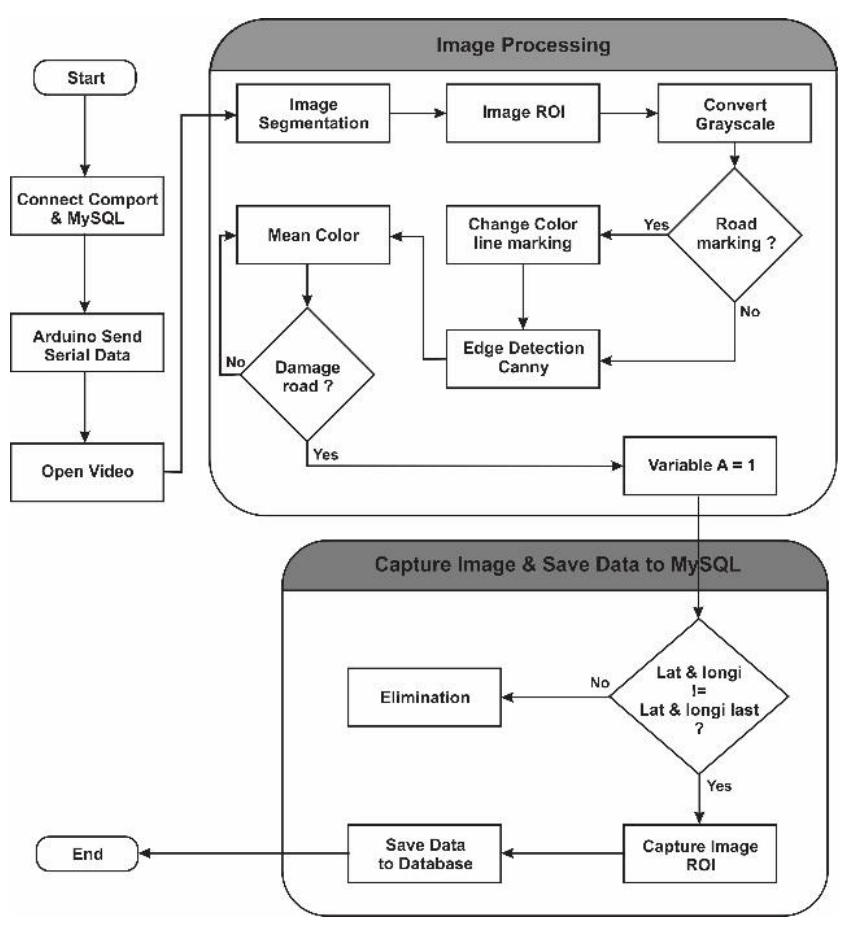

Fig. 3. System Algorithm.

\section{Results and Discussion}

\subsection{GPS Module Testing}

Testing on GPS module was done to know the accuracy level of U-Block NEO 6M GPS module used in displaying latitude and longitude point of a location and its value would be 
compared with GPS in a smartphone. Testing was done three times with different location. The results of this test can be seen in table 1 .

Table 1. GPS module testing.

\begin{tabular}{llll}
\hline \multicolumn{1}{c}{ Location } & \multicolumn{1}{c}{ U-Block NEO 6M GPS } & \multicolumn{1}{c}{ Smartphone GPS } & Difference \\
\hline \multirow{2}{*}{ Meeting Hall } & lat: -7.126269 & lat: -7.126289 & 0.000020 \\
& longi: 112.725135 & longi: 112.725194 & 0.000059 \\
Gopal Rental House & lat: -7.134859 & lat: -7.134918 & 0.000059 \\
& longi: 112.716789 & longi: 112.716836 & 0.000047 \\
Cakra Building & lat: -7.129254 & lat: -7.129281 & 0.000027 \\
& longi: 112.724975 & longi: 112.724941 & 0.000034 \\
\hline
\end{tabular}

Table 1 shows the comparison of latitude and longitude data obtained from the NEO $6 \mathrm{M}$ U-Block GPS module and Smartphone GPS.

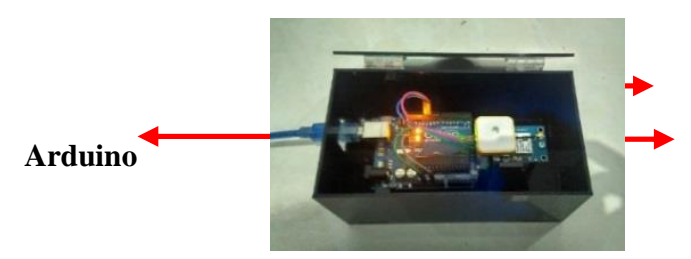

Fig. 4. GPS Module Testing.

Figure 4 is a GPS module testing to get the data about latitude and longitude of a location.

\subsection{Road Damage Detection Test}

This test was conducted to determine the level of success of the system in detecting the object of road damage. The tests were conducted on three different road conditions: a road object with no marking and no shadow, a road object with marking but with no shadow, and a road object with/without marking with shadow. Each road condition was performed two tests on different roads with a vehicle speed of $\pm 20 \mathrm{~km} / \mathrm{h}$.

The first test was performed on a road object with no marking and no shadow. This test was conducted on the road of Kamal Eastern Port and the direction of Labang Village, where the test result data is shown in table 2 . 
Table 2. Test result data on a road object with no marking and no shadow.

\begin{tabular}{l|ll}
\hline Object of Road Damage & Canny Edge Detection & Description \\
\hline & Detected & Detected \\
& & Detected \\
& & Detected \\
& & Detected \\
\hline & & Detected \\
& & but failed capture \\
\hline
\end{tabular}

The second test was performed on a road object with marking but with no shadow . This test was done on the road of Graha Housing to the road of Eastern Gili and the road of Eastern Gili to Graha Housing, where the test result data is shown in table 3.

Table 3. Test result data on a road object with marking with no shadow.

\begin{tabular}{lll}
\hline Object of Road Damage & Canny Edge Detection & \multicolumn{1}{c}{ Description } \\
\hline & Detected \\
& Detected \\
& Detected \\
& Detected \\
& Not Detected \\
& & $\begin{array}{l}\text { Detected } \\
\text { but failed capture }\end{array}$ \\
\hline
\end{tabular}

The third test was performed on a road object with/without marking with shadow. This test was conducted on Talang Asri highway and the road of Trunojoyo Madura Campus Area, where the test result data is shown in table 4. 
Table 4. Test result data on a road object with or without marking with shadow.

\begin{tabular}{lll}
\hline Object of Road Damage & Canny Edge Detection & \multicolumn{1}{c}{ Description } \\
\hline & & Detected \\
& & Detected \\
& & Detected \\
\hline & & Detected \\
\hline
\end{tabular}

Of the six tested road locations, the following table 5 is the percentage of success and failure of detection of road damage objects at each location

Table 5. Percentage of success and failure of detection of road damage objects from tested road locations

\begin{tabular}{llll}
\hline No & \multicolumn{1}{c}{ Road Location } & Success Percentage (\%) & Fail Percentage (\%) \\
\hline 1 & Kamal Eastern Port & $91,30 \%$ & $8,70 \%$ \\
2 & Direction of Labang Village & $81,82 \%$ & $18,18 \%$ \\
3 & Graha Housing to Eastern Gili & $76,66 \%$ & $23,34 \%$ \\
4 & Eastern Gili to Graha Housing & $73,33 \%$ & $26,67 \%$ \\
5 & Telang Asri Highway & $70,59 \%$ & $29,41 \%$ \\
6 & Trunojoyo Madura Campus Area & $66,67 \%$ & $33,33 \%$ \\
\hline & Average & $76,73 \%$ & $23,27 \%$ \\
\hline
\end{tabular}

\section{Conclusion}

Factors affecting the success of the road damage detection process are very complex, but in this paper, the factors that influenced the success of the road damage detection process consisted of: the shadow of the tree that made the characteristic of road damage lost, the update location delay on the U-Blox NEO 6M GPS module, passing vehicles which were caught on webcam cameras, and the existence of half of pothole characteristics which was the same with a normal road. The road damage detection system using canny edge detection method had the average success rate (of the six tested road locations) of $76 \%$. Other studies have better accuracy results because the data used is different from the data used in our study taken from field data in the district of Kamal Bangkalan. As a future work, applied a method to classify between a road damage object and a normal road after canny edge detection 
method and use a GPS module that has better specifications than the NEO 6M U-Block GPS module, especially in the location update speed section.

\section{References}

[1] M. Mandal, M. Katageri, M. Gandhi, N. Koregaonkar, and S. Sengupta, "Automated Management of Pothole Related Disasters Using Image Processing and Geotagging," Int. J. Comput. Sci. Inf. Technol., vol. 7, no. 6, pp. 97-106, 2015.

[2] B. Idestio and T. B. W. Agung, "Alternative Measurement of Road Hole Area Based on Video Data Apply Threshold-based Marking and GLCM," J. INKOM Univ. Telkom, vol. 7, no. 2, pp. 5765, 2013.

[3] R. R. A. Putra, R. Mardiyanto, and D. Purwanto, "Implementation of Image Registration for Recording Road Conditions with the Global Positioning System (GPS)," Institut Teknologi Sepuluh Nopember (ITS), 2013.

[4] A. Suryowinoto and A. Hamid, "Use of Digital Image Processing with Edge Detection Algorithm in Identifying Road Contour Damage,” J. Inst. Teknol. Adhi Tama Surabaya, pp. 149-154, 2017.

[5] R. V. Nahari and R. Alfita, "Analysis On Land Cover In Municipality Of Malang With Landsat 8 Image Through Unsupervised Classification,” J. Phys. Conf. Ser., vol. 953, no. 1, pp. 1-6, 2018.

[6] R. V. Nahari and R. Alfita, "Identification of Chlorophyll-A Distribution Using Landsat 8 in Madura,” Adv. Sci. Lett., vol. 23, no. 12, pp. 12333-12335, 2017.

[7] R. M. Siringoringo, "Design and Implementation Vehicle Monitoring Based on GPS and SMS," in e-Proceeding of Applied Science, 2015, vol. 1, no. 1, pp. 868-875. 